\title{
A FRAMEWORK OF MOBILE EDUCATIONAL APPLICATION FOR KINDERGARTEN EARLY READING
}

\author{
Abdul Jalil Mohamad ${ }^{1}$ and Muhammad Modi Lakulu ${ }^{2}$ \\ ${ }^{1}$ IPG Kampus Tengku Ampuan Afzan, Kuala Lipis \\ ${ }^{2}$ Universiti Pendidikan Sultan Idris, Tanjong Malim
}

\begin{abstract}
A mobile application running on a mobile device offers a novel, fascinating solution to assist children develop their reading skills. However, a number of existing mobile applications in the market have less attributes of appropriate application for young children. The weaknesses of these applications are due to absence of specific framework dedicated for this area. Therefore, this study is focused to propose a framework of a mobile application for kindergarten early reading by analyzing and synthesizing existing frameworks and guidelines. This study proposed a framework of mobile educational application for kindergarten early reading constructed by three main pillars and 16 elements.
\end{abstract}

\section{KEYWORDS}

Mobile Application, Early Reading, Technology, Pedagogy, Content

\section{INTRODUCTION}

Reading is an important skill and most learning materials are available in written form. Hence, reading skills should be mastered by every child in the early stages. Unfortunately, many young children around the world lack literacy skills when they leave preschool or kindergarten. Mobile applications seem to have a great potential to enhance early reading skills among young children. Compared to traditional personal computer, mobile devices with touch screen features are comfortable for young users [1]. However, a number of the existing mobile applications for kindergarten early reading in market have less attributes of well-designed applications for young children and are unsuitable for early childhood development. Consequently, these applications are less useful and are unable to attract young children to learn.

Mobile educational applications if appropriately developed have a great potential to enhance early reading skills among young children [2]. However, studies indicated that some mobile educational applications do not fit with the needs and developmental levels of children. For instance, O. T. Murray and N. R. Olcese [3] revealed that several mobile applications have been developed without any strong theoretical pedagogies and frameworks. Additionally, many educational applications in the market have less criteria of high-quality educational mobile application such as the ambiguity of interface design, unclear instructions, and inappropriate content [4]. In another study, L. Plowman, and C. Stephen [5] found that some educational applications were designed without appropriate interfaces for children's cognitive capability. Moreover, a study conducted by Michael Cohen Group [6] shows that a majority of existing mobile applications were devoid of appropriate interfaces, lack immediate response, have unclear learning objectives, and contain too many interruptions. Yet, in a recent study, although the application developers claimed that their educational applications are focused on play, in reality the application served a different form of drill and practice and limits the exploration which is a crucial element in children's development [7]. 
The weaknesses of available mobile applications in the market are because there are no comprehensive and specific frameworks for developing mobile applications for kindergarten early reading. This statement has been highlighted by L. H. Shoukry, C. Sturm, and G. H. Galal-Edeen, [8] who cautioned that studies in this field are relatively few and no specific frameworks have been established to help develop mobile applications for early childhood education. Their contention is further reinforced by other researchers, notably by M. M. Neumann, and D. L. Neumann, [1] who indicated that the unavailability of a comprehensive framework for mobile applications for kindergarten setting is because research in this specific area is in its infancy.

Several organizations have focused their efforts on using the emerging digital technology for early childhood education. As interface is deemed appropriate for children, Buckleitner [9] constructed the Children's Interactive Media Rating Instrument. This instrument is a comprehensive guideline that focused on the quality of children software based on six main categories: (1) ease of use, (2) childproof, (3) educational, (4) entertaining, (5) design features, and (6) value. More than a decade later, S. W. Haugland, [10] developed the Haugland Developmental Software Scale guideline comprising a list of specific items to evaluate the developmental appropriateness of learning applications. Essentially, this guideline consists of 38 items that measured 11 components: (1) age appropriateness; (2) child in control; (3) clear instructions; (4) expanding complexity; (5) independence; (6) non-violence; (7) process orientation; (8) real world model; (9) technical features; (10) transformational; and (11) antibiased.

Dealing with issues on digital application for early education, The DATEC project [11], an organization funded by EU released the Guidance for Practitioners on Appropriate Technology in Early Childhood as a guideline that emphasizes developmentally appropriate software or application for young children. In essence, this guideline provides detailed descriptions of eight general principles to early childhood practitioners by focusing on the following particular elements: (1) educational purpose; (2) promote collaboration; (3) incorporate into curriculum and support playful; (4) child-centered approach; (5) transparent and intuitiveness; (6) free from violence and bias; (7) protection of children health and safety; and (8) parent's participation. This framework aims to determine the effectiveness of educational application for young children.

Another study by McManis and Parks [12] observed the creation of a general guideline called Early Childhood Educational Technology Evaluation Toolkit consisting of a range of rating scales for the evaluation of apps. More specifically, this toolkit can be used to analyze the appropriateness of applications by focusing on seven main components: (1) education; (2) appropriateness; (3) child-friendliness; (4) enjoyment; (5) progress monitoring; (6) individualization; and (7) integration.

NAEYC and Fred Rogers Center [13] jointly released a white paper entitled Technology and Interactive Media as Tools in Early Childhood Programs Serving Children from Birth through Age 8 as a general guideline for early childhood practitioners to evaluate digital media contents based on appropriate areas. In this collaborative paper, the authors stress that digital media contents should be carefully selected and deployed by taking into account children's developmental stages. This white paper underlined 14 key points in integrating technology for young children learning: (1) safety for children; (2) decision guiding for integration; (3) judgments for the technology appropriateness; (4) guiding for selecting appropriate technology; (5) the appropriateness with children characteristic; (6) promote active engagement, provide scaffolding and support learning; (7) enhance child performance; (8) provide playful activities, support creativity and exploration; (9) tighten school-home relationship; (10) facilitate routine task; (11) accessible for children with disabilities; (12) applicable for dual language children; (13) the importance of digital literacy; and (14) accountability of digital citizenship. 
Regarding the quality of educational application for early childhood, Fred Rogers Center [13] which is an organization for early learning and children's media, developed a framework for children's quality media. This organization's effort, A Framework for Quality in Digital Media for Young Children: Considerations for Parents, Educators, and Media Creators helps developers to create high quality educational software that promotes active engagement among children. The framework focused on three basic principles about the quality of technology: (1) protection for young children, (2) the consideration on children, content and context, and (3) the verified quality assessment for future improvement.

Sesame Workshop [14], a well-known organization concerning on publication of educational children program, has developed the Best Practices: Designing Touch Tablet Experiences for Preschoolers. This guideline focused on nine aspect of designing the best application for young children; (1) use of characters, (2) interactive design, (3) intuitive gestures, (4) screen design, (5) text, (6) visual layout, (7) visual design, (8) audio design, and (9) intentionality.

\section{Methodology}

The methodology refers to the process of data collection and analyzing. It is a crucial part of the research because it reflects that the study is obtained from relevant data. This study research methodology consists of three steps which are selecting existing frameworks and guidelines, categorizing the elements and, analyzing and synthesizing.

\subsection{Selecting Existing Frameworks and Guidelines}

The selected existing frameworks and guidelines are based on literature review with focus on the incorporating of technology in early childhood education. Table 1 displays the existing frameworks and guidelines used for this study.

Table 1: Existing frameworks and guidelines on technology for young children education

\begin{tabular}{|l|l|}
\hline Author (s) & Frameworks/Guidelines \\
\hline Buckleitner (1985) & Children's Interactive Media Rating Instrument \\
\hline Haugland (1998) & Haugland Developmental Software Scale \\
\hline DATEC (2000) & $\begin{array}{l}\text { Guidance for Practitioner on Appropriate Technology in Early } \\
\text { Childhood }\end{array}$ \\
\hline $\begin{array}{l}\text { McManis and Parks } \\
(2011)\end{array}$ & Early Childhood Educational Technology Evaluation Toolkit \\
\hline $\begin{array}{l}\text { NAEYC and Fred Rogers } \\
\text { Center (2012) }\end{array}$ & $\begin{array}{l}\text { Technology and Interactive Media as Tools in Early Childhood } \\
\text { Programs Serving Children from Birth through Age 8 }\end{array}$ \\
\hline $\begin{array}{l}\text { Fred Rogers Center } \\
(2012)\end{array}$ & $\begin{array}{l}\text { A Framework for Quality in Digital Media for Young Children: } \\
\text { Considerations For Parents, Educators, And Media Creators }\end{array}$ \\
\hline $\begin{array}{l}\text { Sesame Workshop (2012) } \\
\text { Best Practices: Designing Touch Tablet Experiences for Pre- } \\
\text { schoolers }\end{array}$ \\
\hline
\end{tabular}

\subsection{Categorizing the Elements}

In order to propose a structural framework, all elements from existing frameworks and guidelines were categorized based on the established framework of integrating technology in classroom by Mishra and Koehler; Technological, Pedagogical and Content Knowledge (TPACK) [15]. TPACK is a framework for effectiveness of the use of technology in teaching and learning [16]. 
The International Journal of Multimedia \& Its Applications (IJMA) Vol.9, No.4/5/6, December 2017

The proposed framework are constructed by three main pillars; pedagogy, technology and content; pedagogy, technology and content.

Table 2: The elements derived from existing framework

\begin{tabular}{|l|l|l|}
\hline \multicolumn{1}{|c|}{ Technology } & \multicolumn{1}{|c|}{ Pedagogy } & \multicolumn{1}{c|}{ Content } \\
\hline Multimedia & Playful & Appropriateness \\
Ease of Use & Exploration & Educational \\
Interactive & Individualization & Theme \\
Intuitiveness & Scaffolding & Protection \\
Legibility & & \\
Readability & & \\
Profile & & \\
\hline
\end{tabular}

\subsection{Analyzing and Synthesizing}

The analyzed and synthesized proposed framework were based on three main pillars; (1) technology, (2) pedagogy and, (3) content. First, researchers identify the number of each element which appears in existing frameworks and guidelines. Then, the numbers will be converted into percentage.

\section{Methodology}

The methodology refers to the process of data collection and analyzing. It is a crucial part of the research because it reflects that the study is obtained from relevant data. This study research methodology consists of three steps which are selecting existing frameworks and guidelines, categorizing the elements and, analyzing and synthesizing.

\subsection{Technology}

Technology refers to the characteristic of mobile application itself. Table 3 summarized the elements of technology found in the existing frameworks and guidelines.

Table 3: Analysis of the elements of technology

\begin{tabular}{|c|c|c|c|c|c|c|c|}
\hline Authors & 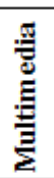 & 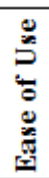 &  & 递 & 总 & 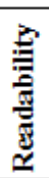 & 롱 \\
\hline Buckleitner (1985) & $\checkmark$ & $\sqrt{ }$ & $\bar{\checkmark}$ & & & & $\sqrt{ }$ \\
\hline Haugland (1998) & $\checkmark$ & & & & & & $\checkmark$ \\
\hline DATEC (2000) & $\checkmark$ & & & $\checkmark$ & & & $\checkmark$ \\
\hline McManis and Parks (2011) & $\checkmark$ & $\checkmark$ & $\checkmark$ & $\checkmark$ & & & $\checkmark$ \\
\hline $\begin{array}{l}\text { NAEYC and Fred Rogers Center } \\
(2012)\end{array}$ & & $\checkmark$ & & & & & \\
\hline Fred Rogers Center (2012) & & $\checkmark$ & $\checkmark$ & & & & \\
\hline $\begin{array}{l}\text { Sesame Workshop } \\
\text { (2012) }\end{array}$ & $\checkmark$ & $\checkmark$ & $\checkmark$ & $\checkmark$ & $\checkmark$ & $\checkmark$ & $\checkmark$ \\
\hline Percentage & 71 & 71 & 57 & 43 & 14 & 14 & 71 \\
\hline
\end{tabular}


According to the results analyzed, the main elements of technology concerning in existing framework are multimedia (71\%), ease of use $(71 \%)$ and profile $(71 \%)$. They are followed by interactive (57\%) and intuitiveness (43\%). Legibility (14\%) and readability (14\%) are very few found in existing frameworks and guideline. However, for this study, researchers also highlighted these two elements due to a reasonable factor. Mobile application for early reading mostly used alphabets and words. Thus, to ensure the efficiency of this mobile application, developers should consider the legibility and readability elements. The mobile application should use appropriate fonts to increase legibility and apply appropriate font size, measure, length and color to increase readability[1].

\subsection{Pedagogy}

Pedagogy elements emphasized the way to deliver the content to children through mobile application[2]-[4].Table 4 shows the elements of pedagogy originally from existing frameworks and guidelines.

From the statistic, the highest percentage of the pedagogy elements is individualization (100\%) and followed by playful (86\%) and exploration (86\%). Result indicated that individualization is an essential element in designing educational application for young children. Beside, scaffolding is also an important element for pedagogy $(71 \%)$.

Table 4: Analysis of the elements of pedagogy

\begin{tabular}{|c|c|c|c|c|}
\hline Authors & $\frac{3}{2}$ &  & 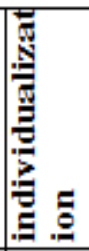 & 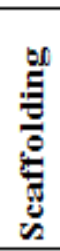 \\
\hline Buckleitner (1985) & & & $\checkmark$ & $\checkmark$ \\
\hline Haugland (1998) & $\checkmark$ & $\checkmark$ & $\checkmark$ & \\
\hline DATEC $(2000)$ & $\checkmark$ & $\checkmark$ & $\checkmark$ & \\
\hline McManis and Parks (2011) & $\checkmark$ & $\checkmark$ & $\checkmark$ & $\checkmark$ \\
\hline NAEYC and Fred Rogers Center (2012) & $\checkmark$ & $\checkmark$ & $\checkmark$ & $\checkmark$ \\
\hline Fred Rogers Center (2012) & $\checkmark$ & $\checkmark$ & $\checkmark$ & $\checkmark$ \\
\hline Sesame Workshop (2012) & $\checkmark$ & $\checkmark$ & $\checkmark$ & $\checkmark$ \\
\hline Percentage & 86 & 86 & 100 & 71 \\
\hline
\end{tabular}

\subsection{Content}

It is important to pay attention on designing content in mobile application for kindergarten early reading. The presentation of the mobile applications content may influence the children engagement and the quality of learning[5]. 
Table 5: Analysis of the elements of content

\begin{tabular}{|c|c|c|c|c|}
\hline Authors & 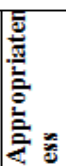 & 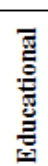 & 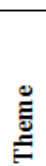 &  \\
\hline Buckleitner (1985) & $\checkmark$ & $\sqrt{ }$ & $\checkmark$ & \\
\hline Haugland (1998) & $\checkmark v$ & & & $\checkmark$ \\
\hline DATEC (2000) & $\checkmark v$ & $\checkmark$ & $\checkmark$ & $\checkmark$ \\
\hline McManis and Parks (2011) & $\checkmark v$ & $\checkmark$ & $\checkmark$ & \\
\hline NAEYC and Fred Rogers Center (2012) & $\checkmark v$ & $\checkmark$ & $\checkmark$ & $\checkmark$ \\
\hline Fred Rogers Center (2012) & $\checkmark$ & $\checkmark$ & & $\checkmark$ \\
\hline Sesame Workshop (2012) & & & $\checkmark$ & \\
\hline Percentage & 86 & 71 & 71 & 57 \\
\hline
\end{tabular}

Table 5 specified the percentage of four content elements in existing frameworks and guidelines. Based on the table, the highest percentage of elements is appropriateness (86\%). To ensure learning experience are valuable, learning objective and activities should be appropriate with children's developmental level[6]. Next, other essential elements of content are educational (71\%) and theme (71\%). According to DATEC[7], the application for young children should have educational value rather than entertainment. Besides, another element for content is protection $(57 \%)$. Protection means the content should free from violence and sexual images.

\subsection{Recommendation}

Towards formulating a comprehensive and specific framework for kindergarten early reading, researchers propose adding a new element; gamification. The advancement of mobile application impacted the way of children's play and learn. Games are very attractive to even young children. As reported by Michael Cohen Group[8], young children are most attracted to mobile games and apps. A research by R. Owston, H. Wideman, N. S. Ronda, and C. Brown, [4]showed games are capable to sustain children's engagement and motivation; and viable to improve literacy skills. Gamification generally defined as incorporated games elements into non games application[9]. To make mobile application for early reading interesting, mobile applications should contain some game elements such as point, badge, level and challenge[10].

\section{Conclusions}

This paper aimed to propose a framework of mobile application for kindergarten early reading through analyzing and synthesizing an existing frameworks and guidelines. For summary, the conclusions for this study are as follows:

i. The proposed framework are constructed by three main pillars; technology, pedagogy, and content.

ii. Due to the advantages of games for young children, researchers also proposed to add a new element namely gamification.

For future works, the researchers should focus on the formulation of the framework by using systematically method and the framework need to validate by respective experts.

The authors would like to thank everyone, just everyone! 
The International Journal of Multimedia \& Its Applications (IJMA) Vol.9, No.4/5/6, December 2017

\section{REFERENCES}

[1] AbilityNet, "Producing accessible materials for print and online," AbilityNet, 2015. [Online]. Available: https://www.abilitynet.org.uk/quality/documents/StandardofAccessibility.pdf. [Accessed: 15-Oct-2015].

[2] M.Kearney, S. Schuck, K. Burden, and P.Aubusson, "Viewing mobile learning from a pedagogical perspective," Res. Learn. Technol., vol. 20, pp. 1-13, 2012.

[3] N.Sazalli and U. Kingdom, "Pedagogical Affordances of Smart Mobile Devices Integrated with Web 2 . 0 Tools to Enhance English Language Teaching and Learning," in Mobile as a MainstreamTowards Future Challenges in Mobile Learning, Springer International Publishing, 2014, pp. 321327.

[4] R.Owston, H.Wideman, N.S.Ronda, and C.Brown, "Computer game development as a literacy activity," Comput. Educ., vol. 53, no. 3, pp. 977-989, 2009.

[5] G.Falloon, "Young students using iPads: App design and content influences on their learning pathways," Comput. Educ., vol. 68, pp. 505-521, 2013.

[6] L.D.McManis and J. Parks, "Evaluating Technology for Early Learners,” Winston-Salem, NC, 2011.

[7] DATEC, "Guidance for Practitioners on Appropriate Technology Education in Early Childhood," DATEC Curriculum Guidance, 2000.[Online].Available: http://www.datec.org.uk/curricguide.htm. [Accessed: 24-Feb-2015].

[8] Michael Cohen Group, "Young Children, Apps \& iPad," 2011.

[9] G.Zichermann and C. Cunnigham, Gamification By Design: Implementing Game Mechanics in Web and Mobile Apps. Canada: O’Reilly Media Inc., 2011.

[10] M.Ahmad, L. A. B. Rahim, and N.I.Arshad,“An analysis of educational games design frameworks from software engineering perspective,” J. Inf. Commun. Technol., vol. 14, no. 1, pp. 123-151, 2015.

\section{Authors}

Abdul Jalil Mohamad is a academic lecturer in IPG Kampus Tengku Ampuan Afzan, Kuala Lipis. His research interest are educational technology and educational mobile application.

Muhammad Modi Lakulu is a Senior Lecturer in Faculty of Art, Computing \& Creative Industry, Universiti Pendidikan Sultan Idris.His research interest are software engineering and knowledge managemen
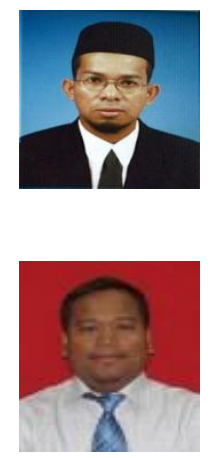